Polymer Journal, Vol. 39, No. 8, pp. 764-776 (2007)

(C) 2007 The Society of Polymer Science, Japan

\title{
Asymmetric Polymerization of (S)-N-Maleoyl-L-Leucine Allyl Ester and Chiral Recognition Ability of Its Polymer as Chiral Stationary Phase for HPLC
}

\author{
Huajing GAO, Yukio IsOBE, Kenjiro ONIMURA, and Tsutomu OISHI ${ }^{\dagger}$ \\ Graduate School of Science and Engineering, Yamaguchi University, 2-16-1 Tokiwadai, Ube 755-8611, Japan
}

(Received February 7, 2007; Accepted April 28, 2007; Published June 19, 2007)

\begin{abstract}
S)$ - $N$-Maleoyl-L-leucine allyl ester ((S)-ALMI), a kind of $N$-substituted maleimide having two double bonds with different reactivities, was newly synthesized from maleic anhydride, L-leucine, and allyl alcohol. Asymmetric polymerizations were carried out to obtain optically active polymers. Poly((S)-ALMI) obtained by anionic polymerization with $n$-butyllithium/( $S, S)$-(1-ethylpropylidene)-bis(4-benzyl-2-oxazoline) ( $n$-BuLi/Bnbox) complex in THF showed the highest negative specific rotation of $-429.1^{\circ}$. Chemoselective polymerization behaviors of $(S)$-ALMI on the two reactive groups were elucidated. In anionic polymerizations, only the double bond in the maleimide moiety exclusively took part in the polymerization, affording the corresponding poly $((S)$-ALMI) with the allyl pendant group. In radical polymerizations, the solvents strongly affect the radical polymerization behaviors of $(S)$-ALMI. Chiroptical properties and structures of the poly $((S)$-ALMI)s obtained were investigated by GPC, CD, XRD, and NMR measurements. The methods of preparing chiral stationary phases (CSPs) for high performance liquid chromatography (HPLC) and the chiral recognition ability of the optically active poly((S)-ALMI) were also discussed.

[doi:10.1295/polymj.PJ2006231]

KEY WORDS Maleimide / Allyl Group / Optically Active Polymer / Asymmetric Polymerization / Chiroptical Properties / Chiral Stationary Phase / HPLC /
\end{abstract}

Asymmetric polymerization is an available method to synthesize optically active polymers. ${ }^{1}$ Many optically active polymers have been widely applied to chiral stationary phases for high performance liquid chromatography (HPLC), polymeric reagents, and catalysts. ${ }^{1-8}$ In the past decades, Oishi et al. have systematically researched syntheses and asymmetric polymerizations of achiral or chiral $N$-substituted maleimides (RMIs) and optical resolution ability of poly(RMI)s. ${ }^{9-26}$ Since RMI consists of an 1,2-disubstituted ethylene structure owning characteristic polymerization reactivity, polymerizations of RMI proceed only through trans-addition to form threo-disyndiotactic and threo-diisotactic main chains. ${ }^{27,28}$ From the previous view, only threo-diisotactic structure can exhibit optical activity due to the excess of $(S, S)$ - or $(R, R)$ chiral stereogenic centers in the main chain, and threo-disyndiotactic one shows no optical activity because of the equal amount of $(S, S)$ - and $(R, R)$-configurations. ${ }^{14,29}$

Amino acids are important and useful substances for chiral auxiliaries and building blocks in organic syntheses. ${ }^{30,31}$ Because the varieties of chiral amino acids are very abundance, we can design a new chiral RMI by introducing expected chiral amino acid to the $\mathrm{N}$-substituent of maleimide. At the same time, various substituents can be easily introduced to the carboxyl group of the side amino acid group in the RMI to get new monomers. From this point of view, we are interested in attaching another polymerizable group to the side amino acid group of chiral RMIs, providing highly optically active polymer through asymmetric polymerizations. Monomers possessing two polymerizable groups with different reactivities would play a new role in polymer reactions and macromolecular networks.

Some monomers that have two polymerizable vinyl groups of identical reactivity such as divinylbenzene, ethylene glycol bis(meth)acrylates, ethylene dimethacrylate are mainly used to prepare crosslinked polymers. ${ }^{32}$ In 1991, Hagiwara et al. reported synthesis and polymerization of $N$-(4-vinylphenyl)maleimide having two polymerizable double bonds with different reactivities. ${ }^{33}$ The two different polymerizable groups could be polymerized selectively without cross-linking by ionic polymerization methods, whereas radical polymerization in THF gave only an insoluble gel. Recently, we have focused on the asymmetric polymerization of chiral RMIs having another reactive group with different reactivity, such as alkenes group or alkynes group. That would open a new research field in the applications of poly(RMI)s. We expect to afford a kind of optically active poly(RMI) with pendant alkenes group or alkynes group. The pendant

${ }^{\dagger}$ To whom correspondence should be addressed (Tel: +81-836-85-9281, Fax: +81-836-85-9201, E-mail: oishi@yamaguchi-u.ac.jp). 
terminal alkenes or alkynes group of such poly(RMI) could react with proper alkoxylsilane to give the labile reactive intermediate via hydrosilylation reaction, which is a very practical and straightforward approach to getting organosilicon compounds. ${ }^{34,35}$ And the obtained reactive intermediate could sequentially react with silica gel to afford chemically-bonded-type CSPs for HPLC to separate racemates. The authors have reported the synthesis and asymmetric polymerization of chiral (S)- $N$-maleoyl-L-leucine propargyl ester $((S)$-PLMI), a kind of RMI possessing a triple bond in the side amino acid group of the $N$-substituent. ${ }^{36,37}$ The two polymerizable groups of ( $S$ )-PLMI were selectively polymerized by using appropriate initiators and solvents. In anionic polymerizations, the $(S)$ PLMI enables the double bond in the maleimide moiety to be exclusively polymerized, retaining potentiality for polymerization or reaction of the triple bonds in the side group of the $N$-substituent.

In this paper, we describe the synthesis and asymmetric polymerization of novel $(S)-N$-maleoyl-L-leucine allyl ester ((S)-ALMI) and the application of its polymer as CSP for HPLC. (S)-ALMI possesses two polymerizable carbon-carbon double bonds with different reactivities, one of which is the olefinic group in the maleimide moiety and the other is allyl group in the ester moiety of the $N$-substituent. Herein, $(S)$ ALMI was polymerized under anionic and radical conditions. The two reactive groups of (S)-ALMI were selectively polymerized by optimizing the reaction conditions. The effects of polymerization conditions on the resulting structures and chiroptical properties of poly $((S)$-ALMI) were investigated in detail on the basis of measurements of nuclear magnetic resonance (NMR), specific rotations, circular dichroism (CD), X-ray diffraction (XRD), and gel permeation chromatography (GPC). Furthermore, the HPLC analyses for separations of racemates using the CSPs prepared from the poly $((S)$-ALMI) are carried out. Optical resolution ability of the chemically-bonded-type CSP is discussed.

\section{EXPERIMENTAL}

\section{Reagents}

Solvents used for syntheses, polymerizations, and measurements were purified in the usual manner. $(S)$ - $N$-Meleoyl-L-leucine $\left((S)\right.$-LMI, ${ }^{37}[\alpha]_{435}=-41.2^{\circ}$ $(c=1.0 \mathrm{~g} / \mathrm{dL}, l=10 \mathrm{~cm}, \mathrm{THF}))$ was synthesized from maleic anhydride and L-leucine. $n$-Butyllithium ( $n$-BuLi) (Kanto Chemical Co., Inc., in $n$-hexane, $1.55 \mathrm{~mol} / \mathrm{L}$ ) was used without further purification. Diethylzinc $\left(\mathrm{Et}_{2} \mathrm{Zn}\right)$ was kindly supplied from Tosoh Corporation, and diluted with purified $n$-hexane (1.04 mol/L). (-)-Sparteine (Sp) (Tokyo Kasei Kogyo
Co., Ltd.) was used after purification by distillation under reduced pressure $\left([\alpha]_{435}=-10.5^{\circ}(c=1.0\right.$ $\mathrm{g} / \mathrm{dL}, l=10 \mathrm{~cm}, \mathrm{THF})$ ). ( $S, S)$-(1-Ethylpropylidene)bis(4-benzyl-2-oxazoline) (Bnbox, $[\alpha]_{435}=-123.5^{\circ}$ $(c=1.0 \mathrm{~g} / \mathrm{dL}, l=10 \mathrm{~cm}$, THF $)$ was prepared according to the published literature. ${ }^{38} 2,2^{\prime}$-Azobisisobutyronitrile (AIBN) (Ishizu Seiyaku, Ltd.) was purified by recrystallization from methanol. Palladiumactivated carbon (Wako Pure Chemical Industries, Ltd., Pd 10\%) was used as purchased. Triethoxysilane (Tokyo Kasei Kogyo Co., Ltd.) and platinum(0)1,3-divinyl-1,1,3,3-tetramethyldisiloxane complex (Sigama Aldrich Inc., $3 \mathrm{Wt} \%$ solution in xylene) were used without further purification. Microporous silica gel (Si-100, pore size $100 \AA$, mean particle size $5 \mu \mathrm{m})$ and racemates were supplied from Tosoh Corporation and used without further purification.

\section{Synthesis of Monomer ((S)-ALMI)}

The synthetic route for the $(S)$-ALMI is depicted in Scheme 1. (S)-LMI (10.0 g, $47.4 \mathrm{mmol})$ was dissolved into thionyl chloride $\left(\mathrm{SOCl}_{2}\right)(50 \mathrm{~mL})$, and the solution was refluxed for $2.5 \mathrm{~h}$. After cooling to room temperature, excess $\mathrm{SOCl}_{2}$ was removed under reduced pressure. The residue $((S)$-LMI-Cl) was dissolved into dry toluene $(150 \mathrm{~mL})$. Allyl alcohol $(4.5 \mathrm{~mL}, 66.4$ mmol) and triethylamine $(8.6 \mathrm{~mL}, 61.6 \mathrm{mmol})$ were dissolved into dry toluene $(150 \mathrm{~mL})$, and the solution was cooled to $0^{\circ} \mathrm{C}$. (S)-LMI-Cl in dry toluene was added dropwise into the above solution. The reaction solution was then heated to $80^{\circ} \mathrm{C}$ and stirred for $11 \mathrm{~h}$. After cooling to room temperature, the solution was washed with $1 \mathrm{~N}$ hydrochloric acid, water, and saturated brine, and dried over $\mathrm{Na}_{2} \mathrm{SO}_{4}$. The solution was concentrated by rotary evaporator to obtain crude (S)-ALMI. The residue was purified by vacuum distillation to obtain ( $S$ )-ALMI as a yellow liquid [yield: $7.8 \mathrm{~g}(65.7 \%)$, bp: $130^{\circ} \mathrm{C} / 0.5 \mathrm{mmHg},[\alpha]_{435}=$ $\left.-36.2^{\circ}(c=1.0 \mathrm{~g} / \mathrm{dL}, l=10 \mathrm{~cm}, \mathrm{THF})\right] .{ }^{1} \mathrm{H}$ NMR $(\delta$ in ppm from TMS in $\left.\mathrm{CDCl}_{3}\right): 6.74(\mathrm{~s}, 2 \mathrm{H},-\mathrm{CH}=\mathrm{CH}-)$, 5.94-5.80 (m, $\left.1 \mathrm{H},-\underline{\mathrm{CH}}=\mathrm{CH}_{2}\right), 5.32-5.21(\mathrm{~m}, 2 \mathrm{H}$, $\left.\mathrm{CH}_{2}=\mathrm{CH}-\right), 4.81-4.75(\mathrm{dd}, 1 \mathrm{H}, J=4.62,4.29 \mathrm{~Hz}$, -CH-N), 4.63-4.61 (m, 2H, $\left.-\mathrm{CH}_{2}-\mathrm{O}\right), 2.32-1.83(\mathrm{~m}$, $\left.2 \mathrm{H},-\mathrm{CH}_{2}-\right), 1.52-1.37\left(\mathrm{~m}, 1 \mathrm{H},-\underline{\mathrm{CH}}-\mathrm{CH}_{3}\right), 0.94-0.90$ $\left(\mathrm{dd}, 6 \mathrm{H}, J=2.64,2.31 \mathrm{~Hz},-\mathrm{CH}_{3}\right) .{ }^{13} \mathrm{C} \mathrm{NMR}(\delta$ in ppm from TMS in $\left.\mathrm{CDCl}_{3}\right)$ : $170.15(\mathrm{C}=\mathrm{O}$ in imide ring), $169.38(\mathrm{C}=\mathrm{O}$ in ester group), $134.25(-\mathrm{CH}=$ $\underline{\mathrm{C}} \mathrm{H}-), \quad 131.42 \quad\left(=\underline{\mathrm{C}}-\mathrm{CH}_{2}\right), \quad 118.67 \quad\left(\underline{\mathrm{CH}}_{2}=\right), \quad 66.29$ $\left(-\mathrm{CH}_{2}-\mathrm{O}\right), 50.69(-\mathrm{CH}-\mathrm{N}), 37.02\left(-\mathrm{CH}_{2}\right), 25.05(-\mathrm{CH})$, $23.09\left(-\mathrm{CH}_{3}\right), 20.88\left(-\mathrm{CH}_{3}\right) . \mathrm{IR}\left(\mathrm{KBr}, \mathrm{cm}^{-1}\right): 3100$, $2970,2880,1745,1710,1464,1405,1390,1255$, 1214, 1175, 1128, 1025, 985, 930, 835, 700. Anal. (\%), Calcd for $\mathrm{C}_{13} \mathrm{H}_{17} \mathrm{NO}_{4}: \mathrm{C}, 62.14 ; \mathrm{H}, 6.82 ; \mathrm{N}$, 5.57. Found: C, 62.37; H. 6.94; N, 5.79. 

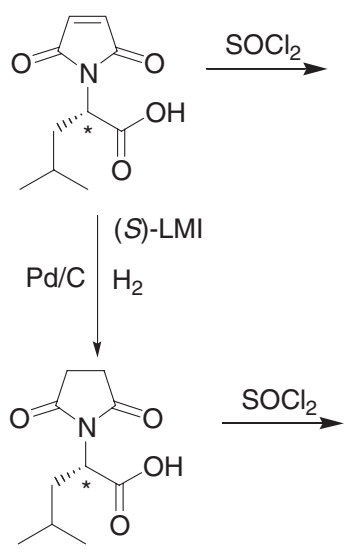

(S)-LSI

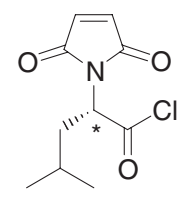

(S)-LMI-CI

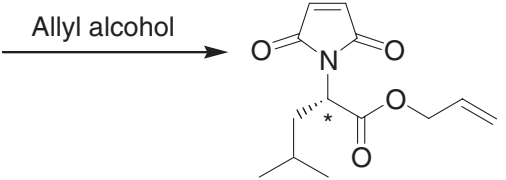

(S)-ALMI

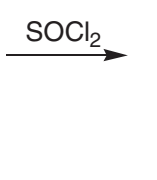

(S)-LSI-Cl

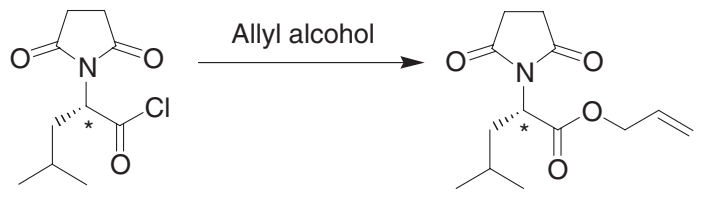

(S)-ALSI

Scheme 1. Syntheses of (S)-ALMI and (S)-ALSI

Synthesis of Model Compound (S)-N-Succinoyl-L-leucine Allyl Ester ((S)-ALSI)

$(S)$-LMI (2 g, $9.4 \mathrm{mmol})$ was dissolved in ethyl acetate $(30 \mathrm{~mL})$ in a Schlenk reaction tube, $10 \mathrm{wt} \%$ palladium-activated carbon $(0.02 \mathrm{~g}, 1 \mathrm{wt} \%$ to $(S)$-LMI) was added. The solution was evacuated by aspirator and replaced by hydrogen gas. After stirring under hydrogen atmosphere for $24 \mathrm{~h}$, the reaction tube was evacuated by aspirator, replaced by nitrogen gas, and then filtered to remove palladium-activated carbon. The filtrate was concentrated under reduced pressure to afford $(S)$-succinoyl-L-leucine $((S)$-LSI) as a yellow liquid [yield: $1.8 \mathrm{~g} \mathrm{(89 \% )].} \mathrm{(S)-ALSI} \mathrm{was} \mathrm{synthesized}$ from (S)-LSI and allyl alcohol (Scheme 1) by the same method as $(S)$-ALMI (yield: $52.9 \%$, yellow liquid, bp: $146^{\circ} \mathrm{C} / 0.5 \mathrm{mmHg},[\alpha]_{435}=-92.6^{\circ}(c=$ $1.0 \mathrm{~g} / \mathrm{dL}, l=10 \mathrm{~cm}, \mathrm{THF})$ ). ${ }^{1} \mathrm{H}$ NMR $(\delta$ in ppm from TMS in $\left.\mathrm{CDCl}_{3}\right): 5.95-5.80\left(\mathrm{~m}, 1 \mathrm{H},-\underline{\mathrm{CH}}=\mathrm{CH}_{2}\right), 5.33-$ $5.22\left(\mathrm{t}, 2 \mathrm{H}, J=14.33 \mathrm{~Hz}, \underline{\mathrm{CH}}_{2}=\mathrm{CH}-\right), 4.85-4.79$ (dd, $1 \mathrm{H}, J=4.32,4.32 \mathrm{~Hz},-\mathrm{CH}-\mathrm{N}), 4.63-4.61$ (d, $2 \mathrm{H}, J=$ $\left.5.68 \mathrm{~Hz},-\mathrm{CH}_{2}-\mathrm{O}\right), 2.76\left(\mathrm{~s}, 4 \mathrm{H},-\mathrm{CH}_{2}-\mathrm{CH}_{2}-\right), 2.25-1.86$ $\left(\mathrm{m}, 2 \mathrm{H},-\mathrm{CH}_{2}\right), 1.49-1.34\left(\mathrm{~m}, 1 \mathrm{H},-\mathrm{CH}-\mathrm{CH}_{3}\right), 0.94-$ $0.91\left(\mathrm{~d}, 6 \mathrm{H}, J=6.49 \mathrm{~Hz},-\mathrm{CH}_{3}\right) .{ }^{13} \mathrm{C} \mathrm{NMR}(\delta$ in ppm from TMS in $\left.\mathrm{CDCl}_{3}\right)$ : $176.41(\mathrm{C}=\mathrm{O}$ in imide ring), $168.79\left(\mathrm{C}=\mathrm{O}\right.$ in ester group), $131.45\left(=\underline{\mathrm{C}}-\mathrm{CH}_{2}\right)$, $118.51\left(\mathrm{CH}_{2}=\right), 66.15\left(-\mathrm{CH}_{2}-\mathrm{O}\right), 51.14(-\mathrm{CH}-\mathrm{N})$, $36.32\left(-\mathrm{CH}_{2}-\right), 27.98 \quad\left(-\mathrm{CH}_{2}-\mathrm{CH}_{2}-\right), 25.00 \quad(-\mathrm{CH})$, $22.97\left(-\mathrm{CH}_{3}\right), 21.04\left(-\mathrm{CH}_{3}\right) . \mathrm{IR}\left(\mathrm{KBr}, \mathrm{cm}^{-1}\right): 2957$, $2871,1779,1745,1710,1465,1395,1260,1190$, 1135, 1029, 980, 930, 822, 664. Anal. (\%), Calcd. $\mathrm{C}_{13} \mathrm{H}_{19} \mathrm{NO}_{4}$ : C, 61.64; H, 7.56; N, 5.53. Found: C, 61.92; H, 7.78; N, 5.62.

\section{Polymerization}

All experiments for polymerization reactions were carried out under purified nitrogen atmosphere to exclude oxygen and moisture. Anionic polymerizations were carried out in the following procedures. Mono- mer and chiral ligand were put in a Schlenk reaction tube and a pear-sharped flask, then evacuated by vacuum pump, and replaced by dry nitrogen gas 5 times. Polymerization solvent (THF or toluene) was added to each vessel by a syringe under nitrogen atmosphere to dissolve them. Organomental ( $n$-BuLi or $\left.\mathrm{Et}_{2} \mathrm{Zn}\right)$ in $n$ hexane solution was introduced into the chiral ligand solution with a syringe to prepare the initiator complex. While the monomer solution was kept at polymerization temperature, the complex solution was added by a cannula in a stream of nitrogen gas to initiate polymerization. After prescribed time, polymerization was terminated with a small amount of methanol containing 2 drops of $6 \mathrm{~N}$ hydrochloric acid. The solution was poured into a large amount of methanol to precipitate polymer, which was then collected by suction filtration, washed with methanol, and dried. Purification of the polymers was achieved by reprecipitation in a THF-methanol system. The obtained polymer was dried under vacuum at room temperature for $2 \mathrm{~d}$ before measurements.

Radical polymerization was conducted with AIBN as an initiator in THF or toluene in a sealed tube at $60^{\circ} \mathrm{C}$ for $24 \mathrm{~h}$. After polymerization, the solution was poured into a large amount of methanol to precipitate the polymer. The obtained product was purified by reprecipitation twice from THF-methanol system, filtered and dried under vacuum at room temperature for $2 \mathrm{~d}$.

\section{Preparation of CSP for HPLC and Column Parking}

Optically active poly $((S)$-ALMI) $(0.035 \mathrm{~g})$ was dissolved in chloroform $(20 \mathrm{~mL})$. Microporous silica gel ( $\mathrm{Si}-100,0.70 \mathrm{~g}$ ) was added to the solution of polymer. After irradiation with ultrasound for $5 \mathrm{~min}$, the mixture was evaporated to dryness under reduced pressure to afford poly((S)-ALMI)-coated-silica gel (CSP 1).

Optically active poly $((S)$-ALMI $) \quad(0.035 \mathrm{~g}, \quad 0.14$ 
mmol) was dissolved in dry toluene $(1.4 \mathrm{~mL})$, and the solution was cooled to $0^{\circ} \mathrm{C}$. To this solution was added platinum(0)-1,3-divinyl-1,1,3,3-tetramethyldisiloxane $(4.2 \mu \mathrm{L}, 0.28 \mu \mathrm{mol})$ and triethoxysilane $(25 \mu \mathrm{L}$, $0.14 \mathrm{mmol}$ ) under argon. Then the resulting mixture was stirred at room temperature for $24 \mathrm{~h}$. As the hydrosilylation reaction of poly((S)-ALMI) was completed, dry toluene $(30 \mathrm{~mL})$ and microporous silica gel $(0.70 \mathrm{~g})$ were added to the mixture. After irradiation of the mixture with ultrasound for 10 seconds, the slurry was refluxed for $4 \mathrm{~h}$ without stirrer and cooled at room temperature. Then the modified silica gel was evaporated under reduced pressure, washed thoroughly with chloroform, and dried in vacuo to afford poly((S)-ALMI)-bonded-silica gel (CSP 2).

CSP 1 and CSP 2 were, respectively, dispersed in 2-propanol and packed into two stainless steel HPLC columns by a high-pressure slurry packing technique using 2-propanol as packing solvent. Theoretical plate numbers of the columns were measured using toluene as standard in $n$-hexane/2-propanol $(9 / 1, \mathrm{v} / \mathrm{v})$ as eluent at a flow rate of $0.5 \mathrm{~mL} / \mathrm{min}$ at $25^{\circ} \mathrm{C}$.

\section{Measurements}

Specific rotations were measured in THF at $25^{\circ} \mathrm{C}$ using a quartz cell $(l=10 \mathrm{~cm})$ with a JASCO DIP140 polarimeter (JASCO Co. Ltd.). CD spectra were recorded in THF at $25^{\circ} \mathrm{C}$ using a quartz cell of $1 \mathrm{~mm}$ with a JASCO J-805 spectropolarimeter (JASCO Co. Ltd.). Number-average molecular weights $\left(M_{\mathrm{n}} \mathrm{s}\right)$ and molecular weight distributions $\left(M_{\mathrm{w}} / M_{\mathrm{n}} \mathrm{s}\right)$ of polymers were determined by a gel permeation chromatography (GPC) using THF $\left(50^{\circ} \mathrm{C}\right)$ as an eluent and polystyrene as a standard on a Shimadzu LC-10A instrument equipped with a SPD-10A UV-vis detector, a polarimetric detector (JASCO OR-990), and a C-R7Ae plus data processor. ${ }^{1} \mathrm{H}(270 \mathrm{MHz})$ and ${ }^{13} \mathrm{C}$ NMR
(68 MHz) spectra were measured on a JEOL-EX270 apparatus (JEOL, Ltd.). FT-IR spectra were recorded in a $\mathrm{KBr}$ disk using FTIR-8100A Fourier transform infrared spectrophotometer (Shimadzu). XRD patterns were obtained by a SHIMADZU XD-D1 at room temperature. HPLC analysis was carried out with an apparatus consisting of a LC-10AT liquid chromatography (Shimadzu), a CTO-10AS column oven (Shimadzu), two CHROMATOPAC C-R8A (Shimadzu), a SPD10A UV detector (254 nm) (Shimadzu), and a JASCOOR 2090 polarimetric detector $(350-900 \mathrm{~nm})$.

\section{RESULTS AND DISCUSSION}

\section{Polymerizations}

Scheme 2 and Table I summarize the conditions and results of the asymmetric anionic polymerizations of (S)-ALMI using $n$-BuLi, $\mathrm{Et}_{2} \mathrm{Zn}$, or $n$-BuLi/ligand, $\mathrm{Et}_{2} \mathrm{Zn}$ /ligand as initiators. All polymerizations proceeded in the homogeneous system from beginning to end, and all of the polymers obtained were soluble in THF and $\mathrm{CHCl}_{3}$. Most of the polymers exhibited negative specific rotations except for run 7 in Table I. The yields of the methanol-insoluble part, the $M_{\mathrm{n}} \mathrm{s}$ and specific rotations of poly $((S)$-ALMI $)$ s were strongly affected by organometals, ligands, and solvents. The yields and $M_{\mathrm{n}} \mathrm{s}$ of poly $((S)$-ALMI)s prepared with

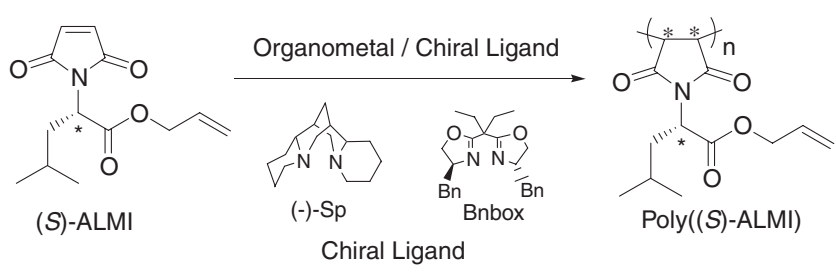

Scheme 2. Anionic polymerization of (S)-ALMI

Table I. Anionic Polymerizations of $(S)-\mathrm{ALMI}^{\mathrm{a}}$ at $0{ }^{\circ} \mathrm{C}$

\begin{tabular}{|c|c|c|c|c|c|c|c|}
\hline Run & Initiator $^{\mathrm{b}}$ & $\begin{array}{l}\text { Polym. } \\
\text { Solv. } \\
(\mathrm{mL})\end{array}$ & $\begin{array}{c}\text { Polym. } \\
\text { Time } \\
\text { h }\end{array}$ & $\begin{array}{c}\text { Yield }^{\mathrm{d}} \\
\%\end{array}$ & $\begin{array}{c}M_{\mathrm{n}}{ }^{\mathrm{e}} \\
\times 10^{-3}\end{array}$ & $M_{\mathrm{w}} / M_{\mathrm{n}}^{\mathrm{e}}$ & $\begin{array}{c}{[\alpha]_{435}{ }^{\mathrm{f}}} \\
\text { deg. }\end{array}$ \\
\hline 1 & $n-\mathrm{BuLi} / \mathrm{Sp}(1.0 / 1.2)$ & Tol. (5) & 72 & 29.8 & 8.7 & 1.3 & -378.6 \\
\hline 2 & $n-\mathrm{BuLi} / \mathrm{Sp}(1.0 / 1.2)$ & THF (5) & 72 & 25.2 & 10.6 & 1.3 & -397.1 \\
\hline 3 & $\mathrm{Et}_{2} \mathrm{Zn} / \mathrm{Sp}(1.0 / 1.2)$ & Tol. (5) & 72 & 46.6 & 15.3 & 1.4 & -101.6 \\
\hline 4 & $\mathrm{Et}_{2} \mathrm{Zn} / \mathrm{Sp}(1.0 / 1.2)$ & THF (5) & 72 & 66.4 & 19.3 & 1.7 & -118.9 \\
\hline 5 & $n$-BuLi/Bnbox $(1.0 / 1.2)$ & Tol. (5) & 72 & trace & - & - & - \\
\hline 6 & $n$-BuLi/Bnbox (1.0/1.2) & THF (5) & 72 & 8.3 & 6.0 & 1.2 & -429.1 \\
\hline 7 & $\mathrm{Et}_{2} \mathrm{Zn} / \mathrm{Bnbox}(1.0 / 1.2)$ & Tol. (5) & 72 & 33.9 & 14.5 & 1.5 & +29.6 \\
\hline 8 & $\mathrm{Et}_{2} \mathrm{Zn} / \mathrm{Bnbox}(1.0 / 1.2)$ & THF (5) & 72 & 27.9 & 13.1 & 1.4 & -98.9 \\
\hline 9 & $n$-BuLi & THF (5) & 72 & 6.1 & 10.2 & 1.2 & -345.6 \\
\hline 10 & $\mathrm{Et}_{2} \mathrm{Zn}$ & THF (5) & 72 & 23.6 & 13.9 & 1.4 & -21.1 \\
\hline
\end{tabular}

aMonomer: $0.5 \mathrm{~g} .{ }^{\mathrm{b}}\left[\right.$ Organometal]/[Monomer] $=0.1$. ${ }^{\mathrm{c}}$ THF: tetrahydrofuran, Tol.: toluene. ${ }^{\mathrm{d}}$ Methanolinsoluble part. ${ }^{\mathrm{e}} \mathrm{By}$ GPC. ${ }^{\mathrm{f}} c=0.1 \mathrm{~g} / \mathrm{dL}, l=10 \mathrm{~cm}$ in THF. 


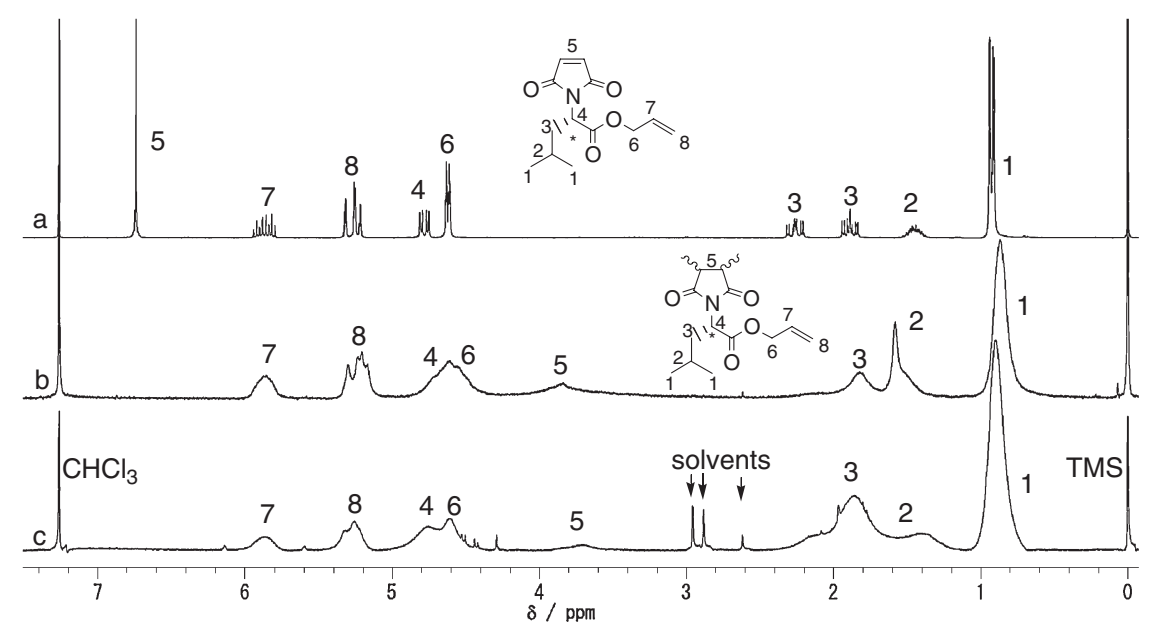

Figure 1. ${ }^{1} \mathrm{H}$ NMR spectra of (S)-ALMI (a) and poly((S)-ALMI)s obtained with $n$-BuLi/Sp in Tol. (b, run 1 in Table I), AIBN in THF (c, run 2 in Table II).

$\mathrm{Et}_{2} \mathrm{Zn}$ or $\mathrm{Et}_{2} \mathrm{Zn} /$ ligand complex were higher than those with $n$-BuLi or $n$-BuLi/ligand complex under the same polymerization conditions. This may result from that the reactivity of the propagating species with $\mathrm{Et}_{2} \mathrm{Zn}$ is relatively higher than that with $n$-BuLi although the initiating reactivity of $\mathrm{Et}_{2} \mathrm{Zn}$ is lower than $n$-BuLi. The absolute values of the specific rotations of polymers obtained with $n$-BuLi or $n$-BuLi/ ligand complexes were much higher than those with $\mathrm{Et}_{2} \mathrm{Zn}$ or $\mathrm{Et}_{2} \mathrm{Zn} /$ ligand complex. This tendency could be attributable to the differences of structures between counter metal cations at the propagating chain end. In the case of the polymerization with $n$-BuLi, the $n$ butyl group initiates the polymerization to afford the corresponding propagating species forming the ion pair with the lithium cation which has no alkyl group at all. On the other hand, in the polymerization with $\mathrm{Et}_{2} \mathrm{Zn}$, either of two ethyl groups of $\mathrm{Et}_{2} \mathrm{Zn}$ initiates the polymerization, therefore, the propagating chain end makes the ion pair with the zinc cation bearing one ethyl group. In the current polymerization system, the remaining ethyl group, which should dominate the polymerization together with the chiral ligand coordinating to the zinc cation, could be unfavorable for the enantio-controlled reaction of the active species with the monomer. The highest specific rotation of poly$((S)$-ALMI) was obtained with $n$-BuLi/Bnbox in THF (run 6 in Table I, $[\alpha]_{435}=-429.1^{\circ}$ ). Compared with the results obtained with $\mathrm{Et}_{2} \mathrm{Zn}$ and $\mathrm{Et}_{2} \mathrm{Zn}$-chiral ligand, the use of chiral ligands (Bnbox and Sp) promotes increasing the yield of poly $((S)$-ALMI) because catalytic activity of the $\mathrm{Et}_{2} \mathrm{Zn} /$ ligand complex was higher than that of $\mathrm{Et}_{2} \mathrm{Zn}$. Interestingly, there was the difference in such reaction-promoting effect between chiral ligands, i.e., the effectiveness of $\mathrm{Sp}$ was better than that of Bnbox, comparing runs 3, 4, 7, 8 with run 10 in Table I. For the poly $((S)$-ALMI)s obtained with the complex of Sp and organometal, the $M_{\mathrm{n}} \mathrm{s}$ and specific rotations of polymers obtained in polar solvent THF were higher than those in toluene (comparing runs 2 and 4 with runs 1 and 3 ). We speculate that the oxygen of THF coordinates with organometal to form an organometal/THF/Sp complex, and the chiral space built up in the growing chain end with such organometal/THF/Sp complex is more suitable for the asymmetric polymerization than only with the organometal/Sp complex. ${ }^{17}$

To investigate structures and anionic polymerization behaviors of poly $((S)-\mathrm{ALMI}) \mathrm{s}$, NMR spectra were measured. The typical ${ }^{1} \mathrm{H}$ NMR spectrum of poly $((S)$-ALMI)s obtained by anionic polymerization is shown in Figure 1(b). The olefinic protons signal of (S)-ALMI at $6.74 \mathrm{ppm}$ completely disappeared and a new broad signal assigned to the methine protons of the polymer main chain appeared around $3.7-4.0 \mathrm{ppm}$. At the same time, the typical allyl protons signals around 5.2-5.9 ppm were observed with the unchanged intensity ratio in comparison with the methylene protons of the allyl ester and the methine proton of the leucine group. These spectral data indicate that the allyl group did not take part in the polymerization, and only the olefinic group in the maleimide moiety of (S)-ALMI was exclusively polymerized to give poly $((S)$-ALMI) with the pendant allyl groups without cross-linking during the anionic polymerization. This indicates that two double bonds of (S)-ALMI have different reactivities-the reactivity of olefinic group in the maleimide moiety relative to the allyl group is quite high, and the olefinic group could undergo chemoselective anionic polymerization. Most of the polymers (except for runs 7 and 10 in Table I) had higher negative specific rotations than the model compound $(S)$-ALSI $\left([\alpha]_{435}=-92.6^{\circ}\right)$, suggesting that asymmetric inductions occurred in 
Table II. Radical Polymerizations of $(S)$-ALMI and $(S)$-ALSI with AIBN at $60^{\circ} \mathrm{C}$

\begin{tabular}{cccccccc}
\hline Run & Monomer $^{\mathrm{a}}$ & $\begin{array}{c}\text { Polym. } \\
\text { Solv. } \\
(\mathrm{mL})\end{array}$ & $\begin{array}{c}\text { Polym. } \\
\text { Time } \\
\mathrm{h}\end{array}$ & $\begin{array}{c}\text { Yield } \\
\%\end{array}$ & $\begin{array}{c}M_{\mathrm{n}}{ }^{\mathrm{d}} \\
\times 10^{-3}\end{array}$ & $M_{\mathrm{w}} / M_{\mathrm{n}}{ }^{\mathrm{d}}$ & $\begin{array}{c}{[\alpha]_{435}{ }^{\mathrm{e}}} \\
\text { deg. }\end{array}$ \\
\hline 1 & $(S)$-ALMI & Tol. (2) & 24 & 100 & - & - & - \\
2 & $(S)$-ALMI & THF (2) & 24 & 37.4 & 8.1 & 1.7 & -115.6 \\
\hdashline 3 & $(S)$-ALSI & Tol. (2) & 24 & 0 & - & - & - \\
4 & $(S)$-ALSI & THF (2) & 24 & 0 & - & - & - \\
\hline
\end{tabular}

${ }^{\mathrm{a}}$ Monomer: $0.5 \mathrm{~g}$. [AIBN]/[Monomer] $=0.1 .{ }^{\mathrm{b}} \mathrm{THF}$ : tetrahydrofuran, Tol.: toluene. ${ }^{\mathrm{c}}$ Methanol-insoluble part. ${ }^{\mathrm{d}}$ By GPC. ${ }^{\mathrm{e}} c=0.1 \mathrm{~g} / \mathrm{dL}, l=10 \mathrm{~cm}$, in THF.

the main chains of these polymers. The polymers with high negative specific rotations would possess $(R, R)$ main-chain configuration more than $(S, S)$-one, judging from the previous research by some of the authors. ${ }^{14,21}$

The results of radical polymerizations of $(S)$-ALMI and $(S)$-ALSI with AIBN as an initiator are shown in Table II. The radical polymerization behavior of $(S)$ ALMI was strongly influenced by polymerization solvents. When the radical polymerization was carried out in toluene (run 1 in Table II), the material produced was a gel which could not be dissolved in usual organic solvents, such as THF, acetone, $\mathrm{CHCl}_{3}$, DMSO, and so on. Both the olefinic group in the imide moiety and the allyl group in the ester moiety probably took part in the reaction to cause gelation. We presume that the polymer obtained under such polymerization condition should be a cross-linked gel. This result is similar to $N$-(4-vinylphenyl)maleimide, which also got an insoluble gel in the radical polymerization with AIBN in THF. ${ }^{32}$ Interestingly, when the same radical polymerization of (S)-ALMI was carried out in THF (run 2 in Table II), polymerization proceeded in the homogeneous system from beginning to end, and the polymer obtained was a white powder which was soluble in THF, $\mathrm{CHCl}_{3}$, and DMSO. From the ${ }^{1} \mathrm{H}$ NMR spectrum (c in Figure 1) of the polymer obtained in THF (run 2 in Table II), the signal at $6.74 \mathrm{ppm}$ assigned to the olefinic protons completely disappeared, a new broad signal assigned to the main chain methine protons of the polymer was observed around 3.6-3.8 ppm. The signals due to allyl protons around 5.2-5.9 ppm were not changed with respect to the intensity ratio to the methylene protons of allyl group and the methine proton of leucine group. These spectral data indicated that the radical polymerization of (S)-ALMI in THF took place exclusively on the olefinic group of the maleimide moiety, and the allyl group was unreacted during the polymerization. From the above results, we conclude that the radical polymerizations of $(S)$ ALMI with AIBN in different solvents (toluene or THF) proceed in different mechanisms as shown in

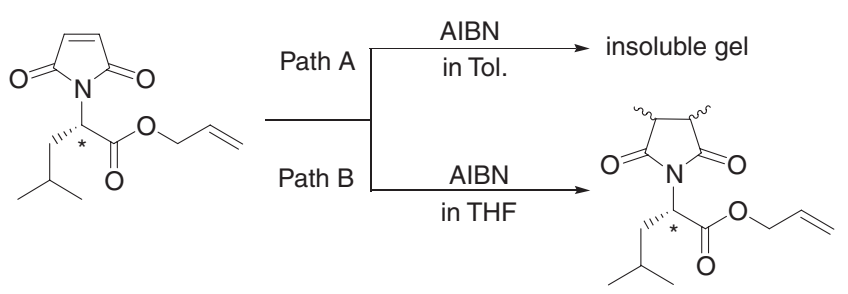

Scheme 3. Two types of radical polymerization modes of (S)-ALMI

Scheme 3. To investigate the reactivity of the allyl group of $(S)$-ALMI in the radical polymerization with AIBN, the model compound of $(S)$-ALSI was polymerized under the same conditions as $(S)$-ALMI (runs 3-4 in Table II). As a result, (S)-ALSI did not afford the corresponding polymers, and the conversions of $(S)$-ALSI were very poor both in toluene and THF. This suggests that the reactivity of allyl group of $(S)$ ALSI in radical polymerization with AIBN was very low. To confirm the effect of solvents on the radical polymerizabilities of two kinds of double bonds in $(S)$-ALMI in detail, radical copolymerizations of $N$ ethylmaleimide and allyl acetate, each of which corresponds to the model compound having one polymerizable group of $(S)$-ALMI, were performed using toluene and THF as solvents. The copolymerization results are summarized in Table III. White copolymers were obtained both in toluene and THF. In the copolymerization in toluene (run 1 in Table III), the copolymer was obtained in $50.0 \%$ yield as a methanol-insoluble fraction, and its $M_{\mathrm{n}}$ was estimated to be 6600 by GPC. ${ }^{1} \mathrm{H}$ NMR spectrum of the copolymer showed that both $N$-ethylmaleimide and allyl acetate took part in the polymerization simultaneously. On the other hand, only a few amount of copolymer was yielded in the copolymerization using THF, ( $8.1 \%$ yield, run 2 in Table III), and its $M_{\mathrm{n}}$ was approximately half of the system in toluene. These results indicate that the present polymerization system involving the reaction of maleimide and allyl moieties is greatly influenced by the solvent, and the use of toluene as the polymerization solvent enhances the reac- 


\section{H. GAO et al.}

Table III. Radical Copolymerizations of Ethylmaleimide $\left(\mathrm{M}_{1}\right)^{\mathrm{a}}$ and Allyl Acetate $\left(\mathrm{M}_{2}\right)^{\mathrm{a}}$ at $60^{\circ} \mathrm{C}$

\begin{tabular}{cccccccc}
\hline Run & Initiator $^{\mathrm{b}}$ & $\begin{array}{c}\text { Polym. } \\
\text { Solv. } \\
(\mathrm{mL})\end{array}$ & $\begin{array}{c}\text { Polym. } \\
\text { Time } \\
\mathrm{h}\end{array}$ & $\begin{array}{c}\text { Yield }^{\mathrm{d}} \\
\%\end{array}$ & $\begin{array}{c}M_{\mathrm{n}}{ }^{\mathrm{e}} \\
\times 10^{-3}\end{array}$ & $M_{\mathrm{w}} / M_{\mathrm{n}}{ }^{\mathrm{e}}$ & $\begin{array}{c}\mathrm{M}_{1}{ }^{\mathrm{f}} \\
\text { in copolymer }\end{array}$ \\
\hline 1 & AIBN & Tol. (2) & 24 & 50.0 & 6.6 & 2.3 & 71.0 \\
2 & AIBN & THF (2) & 24 & 8.1 & 3.6 & 1.2 & 73.1 \\
\hline
\end{tabular}

${ }^{\mathrm{a}} \mathrm{M}_{1}=0.28 \mathrm{~g}, \mathrm{M}_{2}=0.22 \mathrm{~g},\left[\mathrm{M}_{1}\right] /\left[\mathrm{M}_{2}\right]=1 .{ }^{\mathrm{b}}[\mathrm{AIBN}] /\left[\mathrm{M}_{1}+\mathrm{M}_{2}\right]=0.1 .{ }^{\mathrm{c}} \mathrm{THF}:$ tetrahydrofuran, Tol.: toluene. ${ }^{\mathrm{d}}$ Methanol-insoluble part. ${ }^{\mathrm{e}} \mathrm{By}$ GPC. ${ }^{\mathrm{f}} \mathrm{By}{ }^{1} \mathrm{H}$ NMR.

tivity of the allyl-type component. The insoluble gel obtained in the radical polymerization of $(S)$-ALMI would result from the crosslinked network constructed by the reaction of allyl group. The less polymerizability of ally group in THF would lead to the formation of the typical linear maleimide-type polymer having unreacted allyl groups in the side chains.

\section{Chiroptical Properties of Polymers}

Information about chiroptical properties for optically active poly $((S)$-ALMI)s was given by CD and UV spectra. Typical CD and UV spectra of (S)-ALMI, $(S)$-ALSI, and poly $((S)$-ALMI)s obtained by anionic, and radical polymerizations are depicted in Figure 2. The CD spectra of both $(S)$-ALMI and $(S)$-ALSI exhibited a positive Cotton effect around $230-260 \mathrm{~nm}$ (curves 1 and 2 in Figure 2), which was mainly attributable to the $n-\pi^{*}$ transition of carbonyl groups in $N$ substituent. In the CD spectra of poly((S)-ALMI)s obtained by anionic polymerization, the spectral pattern was changed with the specific rotation of the polymer (curves 3-6 in Figure 2). The relative intensities of the CD spectra decreased with the shift of specific rotations toward negative. As levorotation of poly $((S)$ ALMI) increased, the positive Cotton effect around 230-260 nm shifted to zero. When the specific rotations of polymers reached to below $-300^{\circ}$, all of the CD spectra showed the negative Cotton effect (the typical spectrum was shown at curve 4 in Figure 2). This indicated that the new negative CD peak induced by carbonyl groups in the maleimide moiety appeared in the same wavelength region in an addition to the intrinsic CD peak due to chiral $N$ substituent. These results demonstrate that poly $((S)$ ALMI)s with large negative specific rotations possess asymmetric carbons not only in the $N$-substituent, but also in the main chain. The polymer obtained by radical polymerization (run 2 in Table II) exhibited a similar spectral pattern (curve 7 in Figure 2) to (S)-ALSI (curve 2 in Figure 2), suggesting that asymmetric induction scarcely took place into the polymer backbone and optical activity of the poly((S)-ALMI) predominantly results from chiral $N$-substituents.

To investigate the relationship between optical activities and molecular weights of polymers, GPC chromatograms were traced with UV and polarimetric detectors connected in series. The typical chromatograms are displayed in Figure 3. The top and bottom curves are obtained by polarimetric and UV detections, respectively. For the polymers obtained by anionic polymerization, when the absolute value of specific rotation was higher than that of the model compound $(S)$-ALSI $\left([\alpha]_{435}=-92.6^{\circ}\right)$, the polarimetric chromatogram was in good agreement with UV one ( $\mathrm{a}$ and $\mathrm{b}$ in Figure 3). Similar results were observed in the same case for the polymer obtained by the radical polymerization in THF (e in Figure 3). This indicates that every molecular weight part of the polymer possessed the equivalent optical rotation. Namely, optical activities of these poly $((S)$-ALMI)s were independent of the molecular weights. But when the absolute value of the specific rotation of $\operatorname{poly}((S)$ ALMI) was lower than that of model compound $(S)$ ALSI (runs 7 and 10 in Table I), the situation was different. The polarimetric chromatograms displayed two peaks consisting of levorotation and dextrorotation, while each of the UV curves exhibited a single peak (c and d in Figure 3). These indicated that different molecular weight parts of the polymers have different optical rotations. The higher molecular weight parts of the two polymers exhibit dextrorotation and the lower molecular weight parts tend to levorotation. These characteristic $\alpha_{\mathrm{Hg}}$ chromatograms can be explained as follows: one possibility is that the higher molecular weight parts of the polymers contain more $(S, S)$ configurations than $(R, R)$-ones in the main chains of poly $((S)$-ALMI)s, which is newly induced during the polymerizations in the addition to intrinsic levorotation due to the L-leucine residue; Another possibility is that the new chiral conformation with high dextrorotatory is spontaneously formed in the high molecular weight parts of poly $((S)$-ALMI $)$ s. Both of two polymers (runs 7 and 10 in Table I) were obtained by the anionic polymerization with $\mathrm{Et}_{2} \mathrm{Zn}$ as organometal in initiators. We presume that organometal $\mathrm{Et}_{2} \mathrm{Zn}$ has tendency to produce more $(S, S)$-configuration than $(R, R)$-one in the main chain of poly $((S)$ ALMI) and the conformations of polymers might also have effects on the optical activities of poly $((S)$ ALMI)s. 

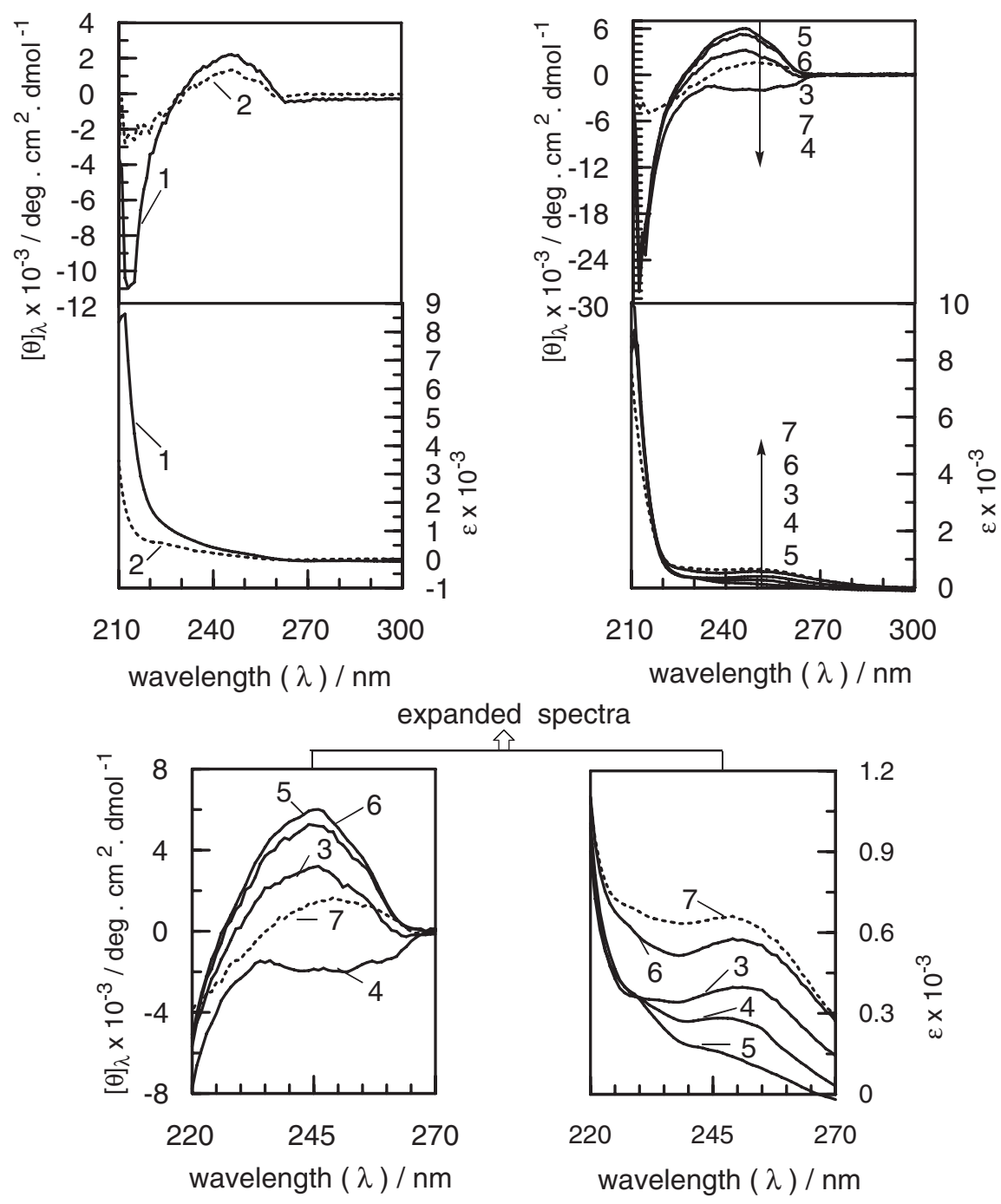

Figure 2. $\mathrm{CD}$ and UV spectra of $(S)$-ALMI $\left(1,[\alpha]_{435}=-36.2^{\circ}\right),(S)$-ALSI $\left(2,[\alpha]_{435}=-92.6^{\circ}\right)$, and poly $((S)$-ALMI)s obtained with $\mathrm{Et}_{2} \mathrm{Zn} / \mathrm{Sp}$ in THF $\left(3,[\alpha]_{435}=-118.9^{\circ}\right.$, run 4 in Table I), $n$-BuLi/Bnbox in THF $\left(4,[\alpha]_{435}=-429.1^{\circ}\right.$, run 6 in Table I), Et ${ }_{2} \mathrm{Zn} / \mathrm{Bnbox}$ in Tol. $\left(5,[\alpha]_{435}=+29.1^{\circ}\right.$, run 7 in Table I), $\operatorname{Et}_{2} \mathrm{Zn}$ in THF $\left(6,[\alpha]_{435}=-21.1^{\circ}\right.$, run 10 in Table I), and $\operatorname{AIBN}$ in THF $\left(7,[\alpha]_{435}=-115.6^{\circ}\right.$, run 2 in Table II).

To obtain more structural information on poly $((S)$ ALMI), ${ }^{13} \mathrm{C}$ NMR spectra were measured. Figure 4 shows typical ${ }^{13} \mathrm{C}$ NMR spectra of poly $((S)$-ALMI)s obtained with $n$-BuLi/Sp (a), $\mathrm{Et}_{2} \mathrm{Zn} / \mathrm{Sp}$ (b), and AIBN (c). All peaks of poly((S)-ALMI)s obtained in anionic polymerizations (a and $b$ ) were sharper than that obtained in radical polymerizations (c). The difference in signals can be obviously confirmed in the expanded main chain peaks in Figure 4. Based on our previous researches, $, 914,16,39,40$ the peaks at lower magnetic field (about $43.5 \mathrm{ppm}$ ) and higher one (about $42 \mathrm{ppm})$ are assigned to threo-disyndiotactic and threo-diisotactic structures of the main chain, respectively. Poly $((S)$-ALMI)s obtained with anionic polymerization ( $\mathrm{a}$ and $\mathrm{b}$ in Figure 4) exhibited clear peaks in the main chain region while only ambiguous peaks were observed over the same region for $\operatorname{poly}((S)$ ALMI) obtained with radical polymerization (c in
Figure 4). This indicates that poly((S)-ALMI) prepared by anionic polymerization possesses the higher stereoregularity. On the other hand, compared with the main chain signals for poly((S)-ALMI)s obtained by anionic polymerization ( $a$ and $b$ in Figure 4 ), the predominant main chain structure was quite different between them, that is, poly $((S)$-ALMI)s with a higher levorotation (a in Figure 4) and a lower levorotation (b in Figure 4) contain a threo-disyndiotactic-rich structure and a threo-diisotactic-rich one, respectively. As can be discussed in the CD analysis, poly $((S)$ ALMI)s with higher negative specific rotations possess higher chirality in the main chains. Therefore, enantio purity of poly $((S)$-ALMI) formed with $n$ $\mathrm{BuLi} / \mathrm{Sp}\left([\alpha]_{435}=-397.1^{\circ}\right)$ would be much higher than that with $\mathrm{Et}_{2} \mathrm{Zn} / \mathrm{Sp}\left([\alpha]_{435}=-115.6^{\circ}\right)$.

XRD spectra were measured to investigate the structures of optically active poly $((S)$-ALMI)s (runs 


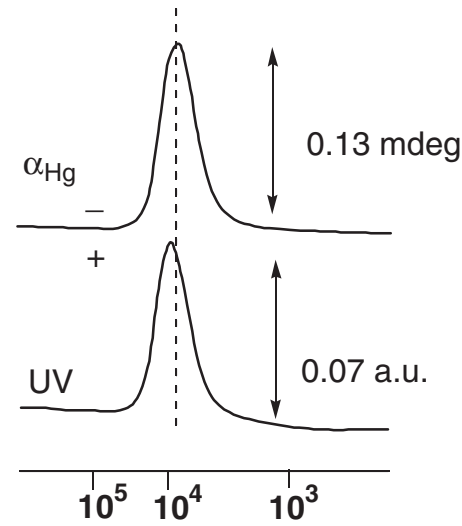

(a)

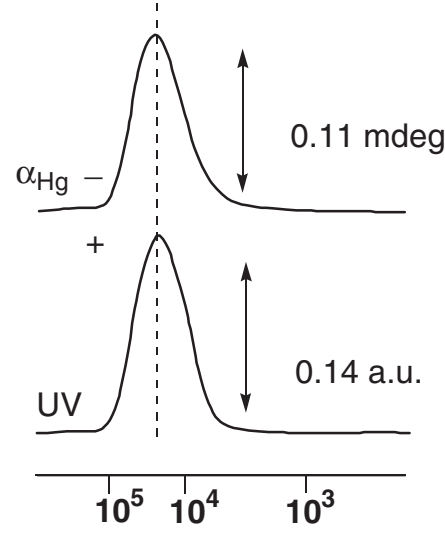

(b)

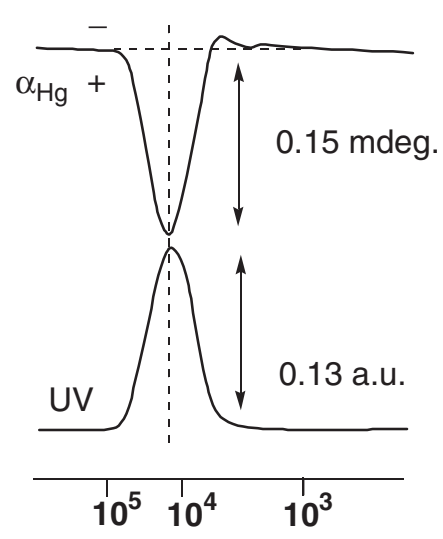

(c)

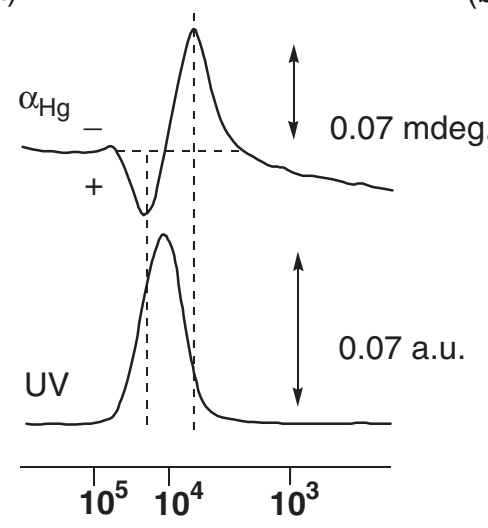

(d)

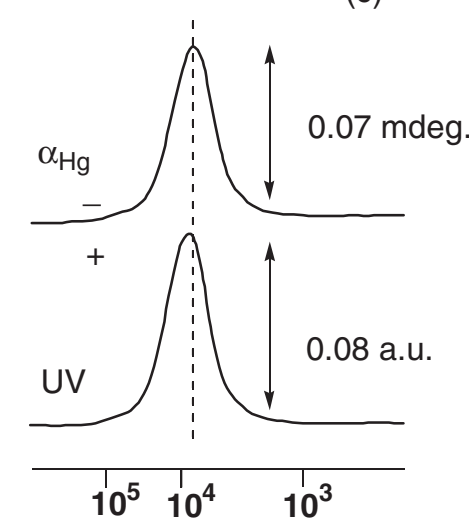

(e)

Figure 3. GPC chromatograms of poly ((S)-ALMI)s obtained with $n$-BuLi/Sp in Tol. (a, $[\alpha]_{435}=-378.6^{\circ}$, run 1 in Table I), Et $2 \mathrm{Zn} / \mathrm{Sp}$ in THF (b, $[\alpha]_{435}=-118.9^{\circ}$, run 4 in Table I), $\mathrm{Et}_{2} \mathrm{Zn} / \mathrm{BnBox}$ in Tol. $\left(\mathrm{c},[\alpha]_{435}=+29.6^{\circ}\right.$, run 7 in Table I), Et ${ }_{2} \mathrm{Zn}$ in THF $\left(\mathrm{d},[\alpha]_{435}=\right.$ $-21.1^{\circ}$, run 10 in Table I), and AIBN in THF $\left(e,[\alpha]_{435}=-115.6^{\circ}\right.$, run 2 in Table II), monitored using UV (bottom curves) and polarmetric $\left(\alpha_{\mathrm{Hg}}\right.$, top curves) detectors.

2, 4 and 7 in Table I). The XRD curves of poly $((S)$ ALMI)s showed no characteristic crystalline peak, indicating that the polymers were almost amorphous.

\section{Chiral Recognition Ability of Poly((S)-ALMI)}

To investigate chiral recognition ability of poly $((S)$ ALMI), two types of CSPs, poly((S)-ALMI)-coatedsilica gel (CSP 1) and poly((S)-ALMI)-bonded-silica gel (CSP 2), were prepared according to synthetic routes of Scheme 4 . In the coated-type CSP, the $\operatorname{polym}((S)$-ALMI) having pendant allyl group was directly and physically coated to silica gel. While in the chemically-bonded-type one, the poly $((S)$-ALMI) was immobilized onto silica gel by side chain via hydrosilylation of functional allyl group with triethoxylsilane and may have an ordered structure. Because the allyl group in the side chain had lower reactivity than the olefinic group in the maleimide moiety and did not take part into the anionic polymerization proved by the former data, we got the optically active poly $((S)$ ALMI) bearing functional double bond on each side chain. This functional polymer can be easily changed into other useful material through addition reactions between the allyl group and other reagents. In this research, the main use of the functional allyl group was chemically bonded the optically active poly $((S)$ ALMI) with silica gel through hydrosilylation. The abilities of CSPs for chiral recognition of racemates 1-37 (Chart 1) were examined with HPLC analysis using the columns showed in Table IV. CSP 1, in which the poly $((S)$-ALMI) (obtained in anionic polymerization, $[\alpha]_{435}=-378.6^{\circ}$, run 1 in Table I) was coated on the surface of silica gel, resolved no racemates listed in Chart 1 both in normal phase system ( $n$-hexane/2-propanol $(9 / 1, \mathrm{v} / \mathrm{v})$ ) and in reversed phase system (methanol $/ \mathrm{H}_{2} \mathrm{O}(7 / 3, \mathrm{v} / \mathrm{v})$ ). While CSP 2, in which the same poly ((S)-ALMI) as used in CSP $1\left([\alpha]_{435}=-378.6^{\circ}\right.$, run 1 in Table I) chemically bonded with silica gel after hydrosilylation with triethoxysilane, resolved racemate 1 (trans-epoxy1-phenyl-3-phenylpropane-3-one) either in normal phase such as $n$-hexane/2-propanol $(9 / 1, \mathrm{v} / \mathrm{v})$ and $n$-hexane $/ \mathrm{CHCl}_{3}(9 / 1, \mathrm{v} / \mathrm{v})$ or in reversed phase such as methanol $/ \mathrm{H}_{2} \mathrm{O}(7 / 3, \mathrm{v} / \mathrm{v})$, and racemate $\mathbf{1 3}$ (trans-epoxy-1-(4-chlorophenyl)-3-phenylpropane-3one) was also resolved on CSP 2 using $n$-hexane/2- 


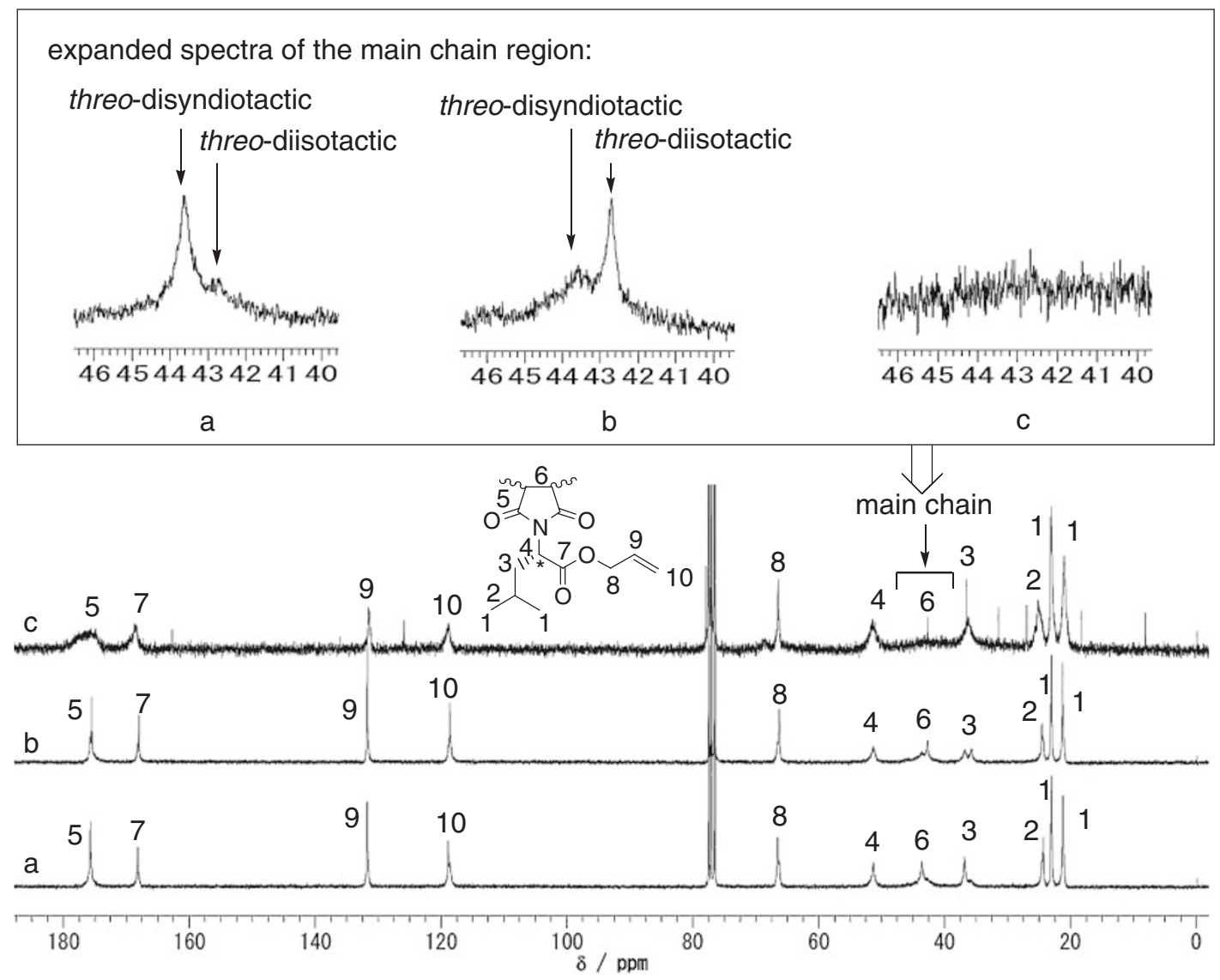

Figure 4. ${ }^{13} \mathrm{C}$ NMR spectra of poly $\left((S)\right.$-ALMI)s obtained with $n$-BuLi/Sp in THF $\left(\mathrm{a},[\alpha]_{435}=-397.1^{\circ}\right.$, run 2 in Table I), Et $2 \mathrm{Zn} / \mathrm{Sp}$ in THF (b, $[\alpha]_{435}=-118.9^{\circ}$, run 4 in Table I), AIBN in THF (c, $[\alpha]_{435}=-115.6^{\circ}$, run 2 in Table II).

(1)

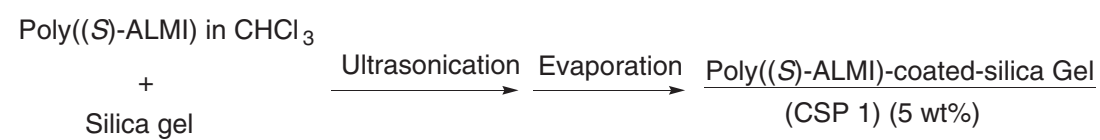

(2)

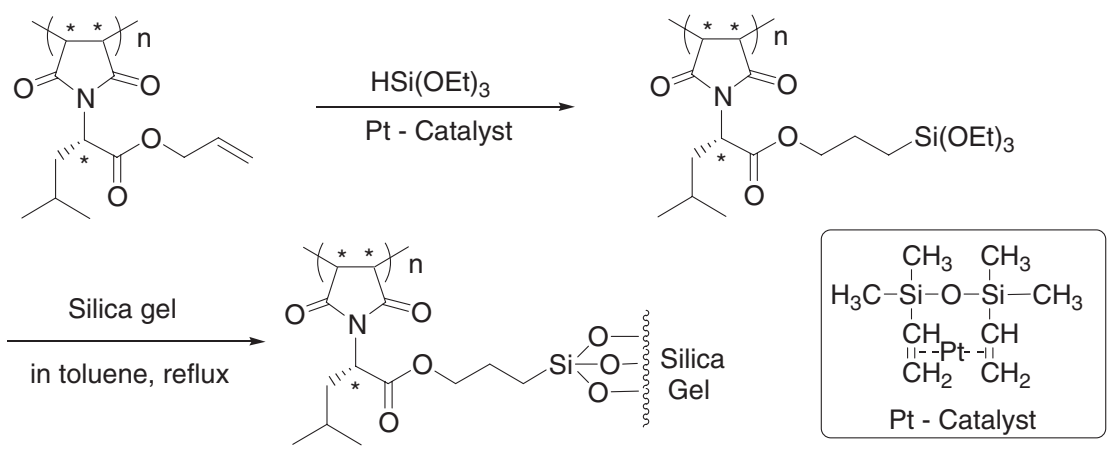

Poly((S)-ALMI)-bonded-silica Gel (CSP 2)

Scheme 4. The Synthetic routes of CSP 1 and CSP 2

propanol $(9 / 1, \mathrm{v} / \mathrm{v})$ as mobile phase. The results are summarized in Table $\mathrm{V}$, and typical chromatograms are shown in Figure 5. From the difference of optical resolution ability between CSP 1 and CSP 2, the chemically-bonded-type CSP of poly $((S)$-ALMI) showed relatively higher chiral resolution ability than the coated-type one and had little limitation on the mobile phase. Comparing to our previous research, ${ }^{37}$ the optically resolution ability of poly $((S)$-ALMI)bonded-type CSP was similar to that of $\operatorname{poly}((S)$ - 


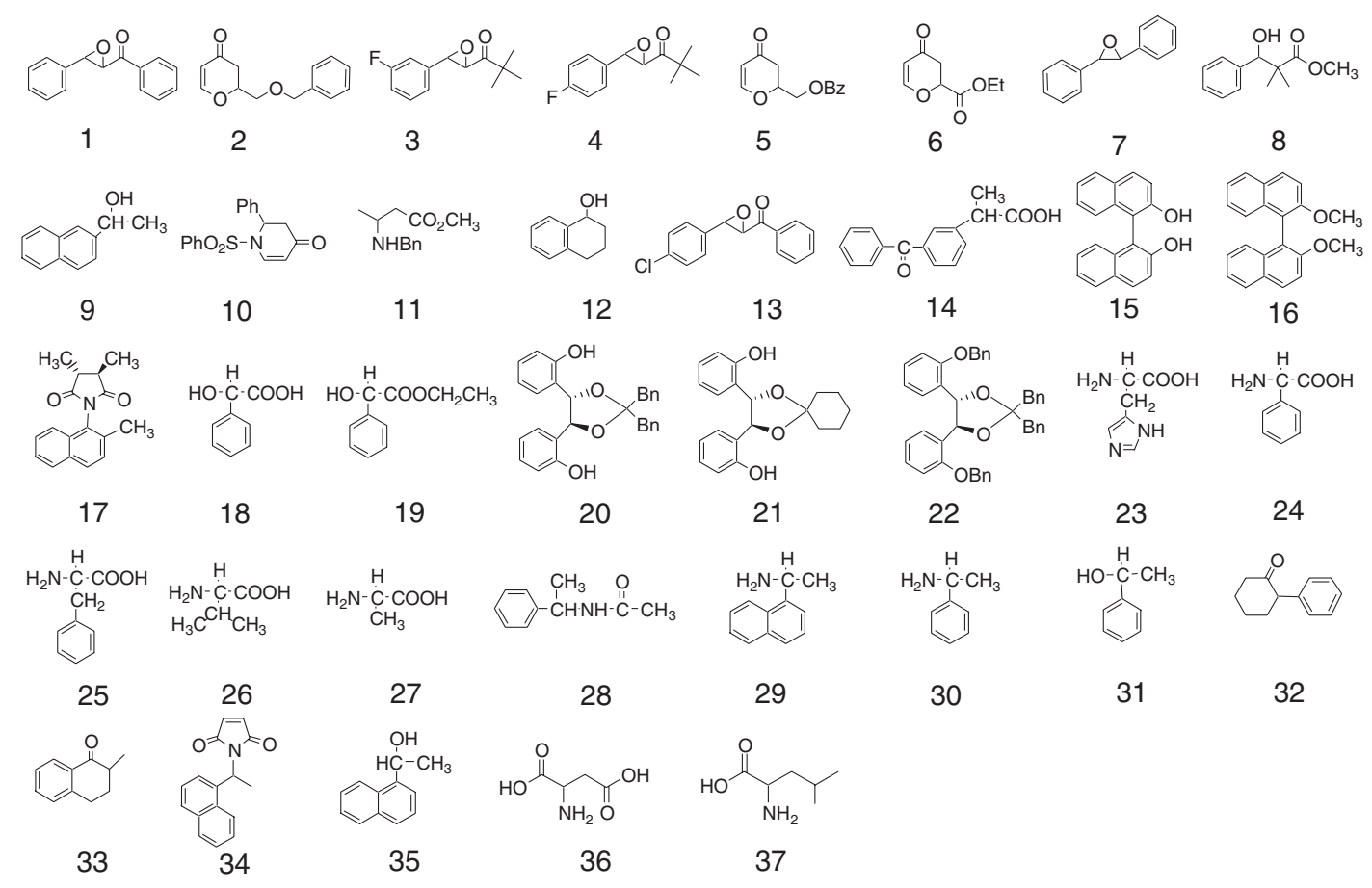

Chart 1.

Table IV. Preparations of Poly $((S)-\mathrm{ALMI})^{\mathrm{a}}$-silica Gel $(\mathrm{Si}-100)^{\mathrm{b}}$ Column $^{\mathrm{c}}$

\begin{tabular}{cccccc}
\hline $\begin{array}{c}\text { Column } \\
\text { No. }\end{array}$ & $\begin{array}{c}\text { Parking } \\
\text { material }\end{array}$ & Dispersant & $\begin{array}{c}\text { Flow Rate } \\
(\mathrm{mL} / \mathrm{min})\end{array}$ & $\begin{array}{c}P_{\max }{ }^{\mathrm{d}} \\
\left(\mathrm{Kg} / \mathrm{cm}^{2}\right)\end{array}$ & $N^{\mathrm{e}}$ \\
\hline 1 & CSP 1 (coated) & 2-propanol & 0.81 & 399 & 947 \\
2 & CSP 2 (bonded) & 2-propanol & 0.71 & 399 & 575 \\
\hline
\end{tabular}

${ }^{\mathrm{a} P o l y}\left((S)\right.$-ALMI): $[\alpha]_{435}=-376.6^{\circ}$ (run 1 in Table I). ${ }^{\mathrm{b}} \mathrm{Si}-100$ : particle size $5 \mu \mathrm{m}$, pore size $100 \AA \AA^{\circ}{ }^{\mathrm{c} C o l u m n}$ size: $150 \times 2.0 \mathrm{~mm}$ I.D. ${ }^{\mathrm{d}}$ Highest pressure to pack CSP into column. ${ }^{\mathrm{e}}$ Theoretical plate number: $N=5.54 \times\left(\mathrm{t}_{\mathrm{r}} / \mathrm{W}_{1 / 2}\right)$.

Table V. Optical Resolution Results Using Column 2

\begin{tabular}{ccccccccccc}
\hline Run & Racemate & $\begin{array}{c}\text { Mobile } \\
\text { Phase } \\
(\mathrm{v} / \mathrm{v})\end{array}$ & $\begin{array}{c}\text { Flow } \\
\text { Rate } \\
(\mathrm{mL} / \mathrm{min})\end{array}$ & $\begin{array}{c}\text { Injected } \\
\text { Volume } \\
(\mu \mathrm{L})\end{array}$ & $t_{1}$ & $t_{2}$ & $k_{1}^{\prime \mathrm{b}}$ & $k_{2}^{\prime \mathrm{b}}$ & $\alpha^{\mathrm{c}}$ & $R_{\mathrm{s}}{ }^{\mathrm{d}}$ \\
\hline 1 & 1 & $\mathrm{Hex} / \mathrm{IPA}(9 / 1)$ & 0.5 & 1.0 & 1.30 & 2.07 & 0.24 & 0.97 & 3.99 & 1.90 \\
2 & 13 & $\mathrm{Hex} / \mathrm{IPA}(9 / 1)$ & 0.5 & 1.0 & 1.32 & 2.60 & 0.26 & 1.48 & 5.57 & 2.47 \\
\hline 3 & 1 & $\mathrm{Hex} / \mathrm{CHCl}_{3}(9 / 1)$ & 0.5 & 1.0 & 2.93 & 3.63 & 1.89 & 2.57 & 1.36 & 1.17 \\
\hline 4 & 1 & $\mathrm{MeOH} / \mathrm{H}_{2} \mathrm{O}(7 / 3)$ & 0.5 & 1.0 & 1.33 & 2.03 & 0.95 & 2.02 & 2.13 & 1.44 \\
\hline
\end{tabular}

${ }^{\mathrm{a}} \mathrm{Hex}$ : $n$-Hexane, IPA: 2-Propanol, $\mathrm{MeOH}$ : Methanol, $\mathrm{CHCl}_{3}$ : Chloroform. ${ }^{\mathrm{b}}$ Capacity factor of enantiomer eluting first $\left(k_{1}^{\prime}\right)$ and second $\left(k_{2}^{\prime}\right)=$ (retention time of enantiomer void time of column)/(retention time of 1,3,5-tri-tertbutylbenzene). ${ }^{\mathrm{c}}$ Separation factor $=k_{2}^{\prime} / k_{1}^{\prime}$. ${ }^{\mathrm{d}}$ Resolution factor $=2 \times($ distance between the peaks of more and less retained enantiomers)/(sum of bandwidth of two peaks).

PLMI)-side group-bonded-type CSP, which the poly $((S)-P L M I)$ also bonded onto the silica gel by the side chain via the hydrosilylation of propargyl group with triethoxylsilane and showed chiral recognition ability to the same racemate 1 both in normal phase and reversed phase. This proved that the unsaturated reactive group in the side chain of $N$-substituted maleimide, such as allyl group or propargyl group, could be an available functional group in preparing CSP for HPLC and play an important role in the recognition. The chemically-bonded-type CSP and the coated-type one had different confirmations and the polymers extended to different orientations on the surface of silica gel because of the different immobilization method. The difference of chiral recognition behavior between two types of CSPs indicated that the 


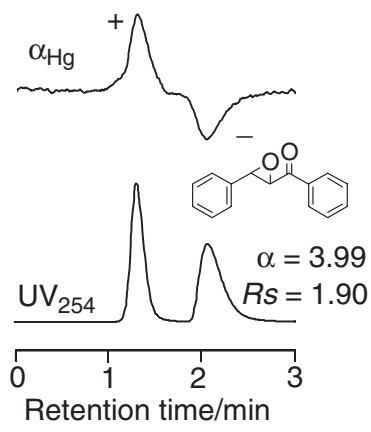

(a)

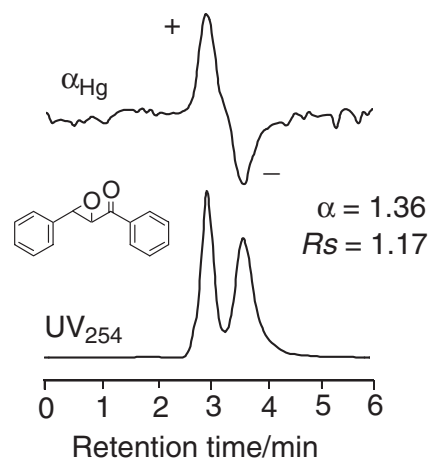

(c)

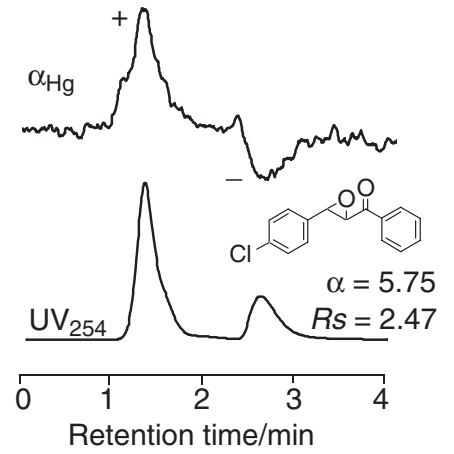

(b)

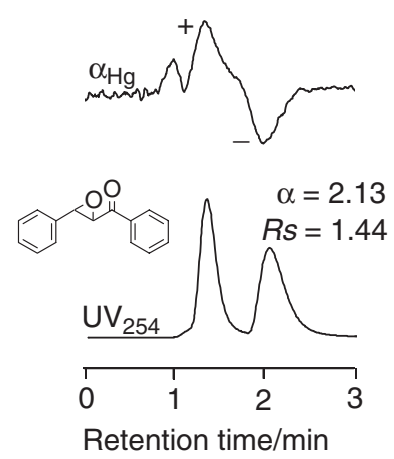

(d)

Figure 5. HPLC resolution chromatograms of racemates with poly((S)-ALMI)-bonded Silica gel (column 2, Table IV) listed in Table V: (a) run 1, (b) run 2, (c) run 3, and (d) run 4 . The top chromatograms were measured by polarimetric detector $\left(\alpha_{\mathrm{Hg}}\right)$ and bottom by UV detector $(254 \mathrm{~nm})$.

conformation of CSP also played a role in the recognition, at the same time, the chemically-bonded-type CSP may have an ordered structure and made more chiral spaces than the coated-type one. According to the data of separation factor and resolution factor, the resolution ability of CSP 2 for racemate 1 in $n$-hexane/2-propanol $(9 / 1, \mathrm{v} / \mathrm{v})$ as mobile phase is higher than that in reversed phase (methanol $/ \mathrm{H}_{2} \mathrm{O}$ $(7 / 3, v / v))$, and that may be ascribed to the H-H-combination of molecular interaction. From the $\alpha_{\mathrm{Hg}}$ chromatograms of HPLC showed in Figure 5, the $(+)$ enantiomers of racemates were eluted at first and the (-) enantiomers were absorbed by the CSP 2 prepared from the poly $((S)$-ALMI) with high levorotation. The chiral discriminability of poly $((S)$-ALMI) may be ascribed not only to the interaction between the polymer and racemates but also to the higher-ordered structures of the polymer.

\section{CONCLUSIONS}

1. A novel chiral monomer (S)-ALMI $\left([\alpha]_{435}=\right.$ $-36.2^{\circ}$ ) bearing two polymerizable carbon-carbon double bonds with different reactivities simultaneously was synthesized.

2. Optically active poly $((S)$-ALMI)s were obtained by asymmetric polymerization. Poly((S)-ALMI) initiated by the $n$-BuLi/Bnbox complex in THF exhibited the highest negative specific rotation $\left([\alpha]_{435}=\right.$ $-429.1^{\circ}$ ).

3. The selective polymerization could occur through anionic polymerizations with organometals, or organometal/chiral ligand complexes and radical polymerization with AIBN in THF-only the olefinic group in the maleimide moiety took part in the polymerizations to give poly $((S)$-ALMI) with pendant allyl groups without cross-linking. Radical polymerization with AIBN in toluene gave an insoluble gel, suggesting that the cross-linked reaction took place.

4. According to the $\mathrm{CD}, \mathrm{XRD}$, and GPC, optical activities of the poly $((S)$-ALMI)s obtained with anionic polymerization were attributed to excessive chiral centers of the main chain induced through the polymerizations in addition to the chirality of the side group. The conformations of polymers might also have effects on the optical activities of $\operatorname{poly}((S)$ ALMI)s.

5. The chemically-bonded-type CSP of $\operatorname{poly}((S)-$ ALMI) resolved racemate 1 by HPLC either in normal phase system such as $n$-hexane/2-propanol $(9 / 1, \mathrm{v} / \mathrm{v})$ and $n$-hexane $/ \mathrm{CHCl}_{3}(9 / 1, \mathrm{v} / \mathrm{v})$ or in reversed phase system such as methanol/ $\mathrm{H}_{2} \mathrm{O}(7 / 3, \mathrm{v} / \mathrm{v})$. 


\section{REFERENCES}

1. Y. Okamoto and T. Nakano, Chem. Rev., 94, 349 (1994).

2. T. Yasuzawa, H. Yamaguchi, and Y. Minoura, J. Polym. Sci., Polym. Chem. Ed., 17, 3387 (1979).

3. K. Ohta, Y. Okamoto, K. Hatada, and H. Yuki, J. Polym. Sci., Polym. Chem. Ed., 17, 2917 (1979).

4. H. Yuki, Y. Okamoto, and I. Okamoto, J. Am. Chem. Soc., 102, 6356 (1980).

5. C. G. Overberger, C. X. Lu, and C. C. Chen, J. Polym. Sci., Part A: Polym. Chem., 24, 75 (1986).

6. E. Yashima, C. Yamamoto, and Y. Okamoto, Synlett, 1998, 344 (1998).

7. T. Takata, Y. Furusho, K. Murakawa, T. Endo, H. Mastuoka, Y. Hirasa, J. Mastuo, and M. Sisido, J. Am. Chem. Soc., 120, 4530 (1998).

8. T. Oishi, K. Onimura, W. Sumida, T. Koyanagi, and H. Tsutsumi, Polym. Bull., 48, 317 (2002).

9. T. Oishi, H. Yamasaki, and M. Fujimoto, Polym. J., 23, 795 (1991).

10. T. Oishi, K. Matsusaki, and M. Fujimoto, Polym. J., 24, 1281 (1992).

11. T. Oishi, Y. Otsubo, and M. Fujimoto, Polym. J., 24, 527 (1992).

12. K. Kagawa and T. Oishi, Polym. J., 27, 579 (1995).

13. T. Oishi, H. Nagata, and H. Tsutsumi, Polymer, 39, 4135 (1998).

14. K. Onimura, H. Tsutsumi, and T. Oishi, Macromolecules, 31, 5971 (1998).

15. K. Onimura, H. Tsutsumi, and T. Oishi, Chem. Lett., 27, 791 (1998).

16. T. Oishi, K. Onimura, K. Tanaka, W. Horimoto, and H. Tsutsumi, J. Polym. Sci., Part A: Polym. Chem., 37, 473 (1999).

17. H. Zhou, K. Onimura, H. Tsutsumi, and T. Oishi, Polym. J., 32, 552 (2000).

18. H. Zhou, K. Onimura, H. Tsutsumi, and T. Oishi, Polym. J., 33, 227 (2001).

19. Y. Isobe, K. Onimura, H. Tsutsumi, and T. Oishi, Macromolecules, 34, 7617 (2001).

20. Y. Isobe, K. Onimura, H. Tsutsumi, and T. Oishi, J. Polym.
Sci., Part A: Polym. Chem., 39, 3556 (2001).

21. T. Oishi, K. Onimura, Y. Isobe, and H. Tsutsumi, Chem. Lett., 28, 673 (1999).

22. Y. Isobe, K. Onimura, H. Tsutsumi, and T. Oishi, Polym. J., 34, 18 (2002).

23. T. Oishi, Y. Isobe, K. Onimura, and H. Tsutsumi, Polym. J., 35, 245 (2003).

24. Y. Zhang, K. Onimura, H. Tsutsumi, and T. Oishi, Polym. J., 36, 878 (2004).

25. K. Onimura, Y. Zhang, M. Yagyu, and T. Oishi, J. Polym. Sci., Part A: Polym. Chem., 42, 4682 (2004).

26. T. Oishi, Y. Zhang, T. Fukushima, and K. Onimura, Polym. J., 37, 453 (2005).

27. K. Kagawa and T. Oishi, Polym. J., 28, 1 (1996).

28. R. C. P. Cubbon, Polymer, 6, 419 (1965).

29. T. Oishi and K. Onimura, Kobunshi Ronbunshu, 59, 287 (2002).

30. G. M. Coppola and H. F. Schuster, "Asymmetric Synthesis: Construction of Chiral Molecules Using Amino Acids," John Wiley \& Sons, Inc., New York, N. Y., 1987.

31. G. Gao, F. Sanda, and T. Masuda, Macromolecules, 36, 3932 (2003).

32. M. Mennicken, R. Nagelsdiek, H. Keul, and H. Höcker, Macromol. Chem. Phys., 205, 2429 (2004).

33. T. Hagiwara, I. Suzuki, K. Takeuchi, H. Hamana, and T. Narita, Macromolecules, 24, 6856 (1991).

34. M. Rubin, T. Schwier, and V. Gevorgyan, J. Org. Chem., 67, 1936 (2002).

35. I. W. Muderawan, T. T. Ong, and S. C. Ng, J. Sep. Sci., 29, 1849 (2006).

36. H. Gao, Y. Isobe, K. Onimura, and T. Oishi, Polym. J., 38, 1288 (2006).

37. H. Gao, Y. Isobe, K. Onimura, and T. Oishi, J. Polym. Sci., Part A: Polym. Chem., in press.

38. S. E. Denmark, N. Nakajima, O. J.-C. Nicaise, A.-M. Faucher, and J. P. J. Edwards, J. Org. Chem., 60, 4884 (1995).

39. T. Oishi, K. Onimura, H. Yanagihara, and H. Tsutsumi, J. Polym. Sci., Part A: Polym. Chem., 38, 310 (2000).

40. Y. Isobe, M. Nakamura, H. Gao, K. Onimura, and T. Oishi, Kobunshi Ronbunshu, 63, 484 (2006). 